\title{
MONITORING REACTIONS IN ALKALINE DIRECT ETHANOL FUEL CELLS ASSEMBLED WITH NON-PT-CATALYST
}

\author{
E. Gülzow ${ }^{\text {a) }}$, M. Beyer ${ }^{\text {a) }}$, K. A. Friedrich ${ }^{\text {a) }}$, \\ S. Pengel $^{\text {b) }}$, P. Fischer ${ }^{\text {b) }}$ and H. Bettermann ${ }^{\text {b) }}$ \\ a) Institute of Technical Thermodynamics, German Aerospace Center (DLR), \\ 70569 Stuttgart, Germany \\ ${ }^{b)}$ Institute of Physical Chemistry I, Heinrich-Heine-Universität Düsseldorf, \\ 40225 Düsseldorf, Germany
}

This contribution shows how Raman spectroscopy can be used to pursue chemical reactions within fuel cells. For this, the oxidation of ethanol occurring in an alkaline direct ethanolic fuel cell was investigated. The analysis of a sequence of Raman spectra recorded during the reaction shows that ethanol was solely oxidized to acetate in a unique reaction.

Direct ethanol fuel cells are key objects of future fuel cell developments. In particular alkaline direct ethanol fuel cells are favored as they feature an increased performance and allow the use of cheaper platinum-free catalysts (1). Possible oxidations of ethanol in alkaline solution are depicted in Fig. 1.

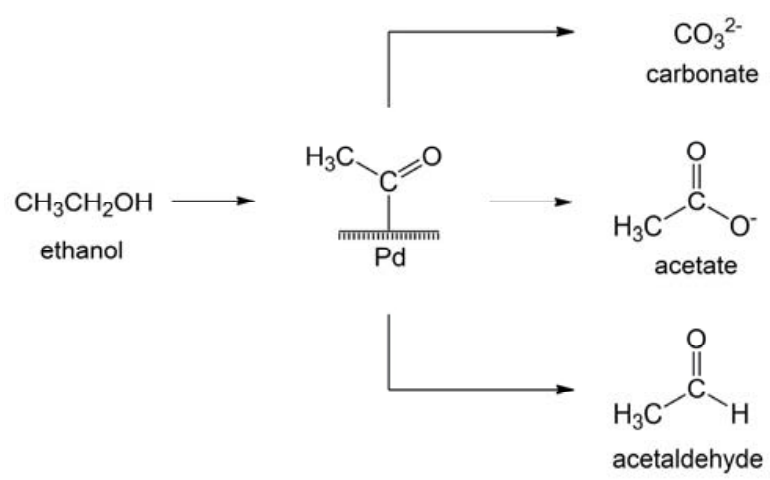

Figure 1. Possible reaction pathways of the ethanol reaction.

Acetate is commonly considered as the main product of the ethanol oxidation reaction (2), (3) . In strong alkaline solutions acetaldehyde and carbonate are regarded as possible side reaction products (4), (5), (6), (7). Acetaldehyde polymerizes under the alkaline conditions via crotonaldehyde to numerous unwanted by-products that causes coating and clogging of the catalyst layer (8). The complete oxidation to carbonate on the other hand is highly desired since it triples the amount of electrons per molecule. The catalytic scission of the $\mathrm{C}-\mathrm{C}$ bond in aqueous media is viewed as a challenging task in catalyst research. Lately catalytic oxidation with palladium alloys or mixtures of fine dispersed 
Palladium palladium with rare earth oxides are considered as a feasible alternative to platinum catalysts. But results of several authors with Pd-catalysts are contradictory, as it remains unclear whether the $\mathrm{C}-\mathrm{C}$ bond of ethanol is cleaved or not. Carbonate is regarded as an indicator for the complete scission of the $\mathrm{C}-\mathrm{C}$ bond, but carbon dioxide uptake from air can falsify the results (4). Therefore strong care must be taken to exclude contact of carbon dioxide with the alkaline ethanol cycle.

In this contribution the oxidation of ethanol was pursued online by Raman spectroscopy. For this, a flow cell was inserted within the fuel cycle. Since Raman spectra exhibit fingerprints of compounds, various compounds can be well distinguished in mixtures even in aqueous solutions. The course of the reaction can be easily monitored by the decay of the Raman signals belonging to the initial compound and the growth of the signal intensities of the reaction product. This exemplarily ethanol oxidation is thought to demonstrate the usefulness of in-situ Raman spectroscopy for the monitoring of the chemical reactions inside fuel cells.

\section{Experimental}

The setup is schematically shown in Fig. 2 and Fig. 3. The cell is made of gold plated stainless steel. The anion exchange membrane (Tokuyama) is placed between two Hypermec electrodes (Acta SpA.) and exhibits an active area of $50 \mathrm{~cm}^{2}$ (Fig. 2). On the anode side, a catalyst is used that contained palladium cerium oxide. The cell is equipped with single serpentine flow fields (cathodic channel: width: $3 \mathrm{~mm}$, depth: $1 \mathrm{~mm}$; anodic channel: width: $4 \mathrm{~mm}$, depth: $1 \mathrm{~mm}$ ).

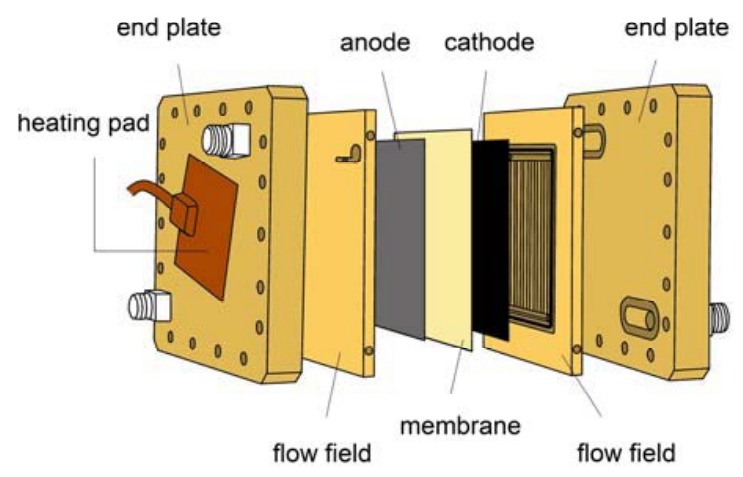

Figure 2. Schematic setup of the DEFC.

The mass flow of the air is set to $200 \mathrm{sccm} \mathrm{min}^{-1}$. The ethanol-solution $(1 \mathrm{M} \mathrm{KOH}, 10$ vol. \% ethanol) is pumped at a rate of $17.2 \mathrm{ml} \mathrm{min}^{-1}$. The cell temperature is set to $50{ }^{\circ} \mathrm{C}$ for the measurements. Since the uptake of $\mathrm{CO}_{2}$ from air is strong in alkaline media, an anodic cycle is built up that is completely separated from its environment. In addition the cycle is continuously purged with nitrogen. The fuel reservoirereservoir consists of a heatable Teflon ${ }^{\mathrm{TM}}$ flask with a total volume of $500 \mathrm{ccm}$. To prevent evaporating of ethanol, the flask is connected to a Dimroth condenser. The condenser is cooled by a refrigerated circulator down to $5{ }^{\circ} \mathrm{C}$. The closed anodic cycle of the DEFC is driven by a regulated gear pump (Fig. 3). The anodic outflow is directed to a flow through cell made 
of polyether ether ketone. The cell is integrated into a self-build Raman microscope described in detail below.

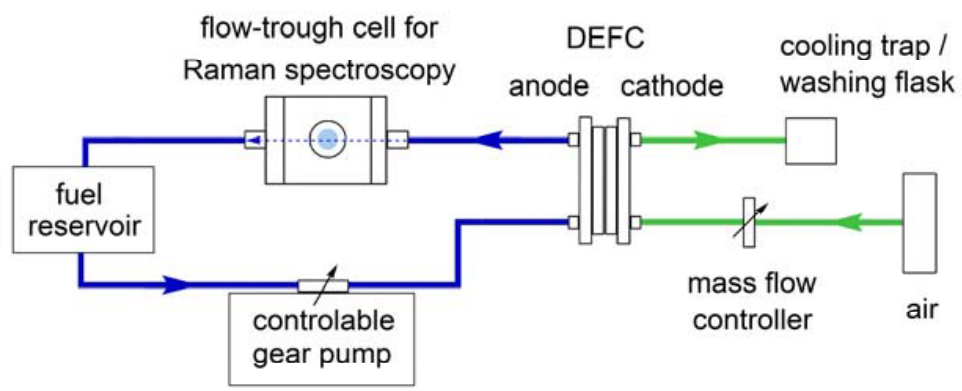

Figure 3. Schematic drawing of the closed electrolyte cycle.

On the cathode side $\mathrm{CO}_{2}$-free synthetic air $\left(\mathrm{CO}_{2}<5 \mathrm{ppm}\right)$ is used to avoid carbon dioxide uptake through the membrane. Normally compressed air is used to demonstrate the $\mathrm{CO}_{2}$ passage through the membrane. Liquids that passed through the membrane are collected by a cold trap on the cathode side and investigated by Raman spectroscopy, UV-Vis spectroscopy as well as mass spectroscopy.

The Raman spectra are recorded with a self-build microscope setup (Fig. 4). The fuel is excited by an argon-ion laser (Spectra Physics, model 2380). The excitation wavelength is set to $514.5 \mathrm{~nm}$. The out coupled power amounts to $1.5 \mathrm{~W}$ and the exposure time is $1 \mathrm{~min}$ for each spectrum. The laser radiation is guided to an Amici-prism, to reject spontaneous plasma emission. The microscopic setup is equipped with a dielectric notch-filter and a microscope objective which focuses the laser radiation in the anodic outflow. The notch-filter reflected the Rayleigh part of the scattered radiation while the Raman scattering is able to pass through and is guided to a monochromator (Kaiser Optical Systems, model Holospec f/1.8). The dispersed scattered light is then directed to a CCD camera (Priceton Instruments, model Pixis $400 \mathrm{~B}$ ) that is cooled down to $-75^{\circ} \mathrm{C}$. The current of the DEFC is controlled by a power potentiostat (Zahner Elektrik, model PP200).

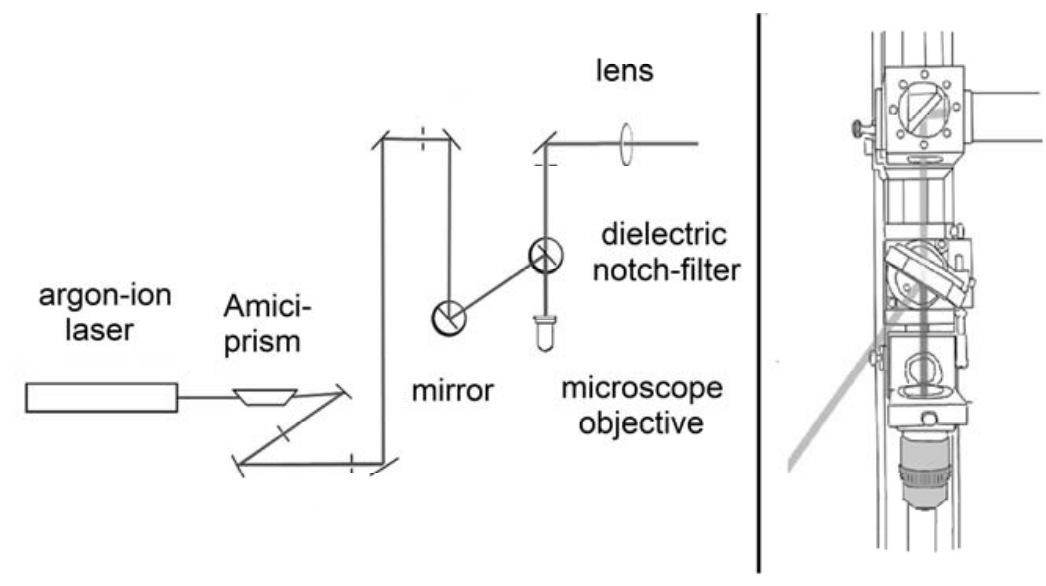

Figure 4. Schematic setup of the Raman spectrometer with a top view and a detail of the microscope setup. 


\section{Results}

A selection of reaction spectra depicted in Fig. 5 presents the time-evolution of educt signals and signals of the reaction products during a $24 \mathrm{~h}$ lasting measurement. The cell is run in galvanostatic mode with a constant current density of $20 \mathrm{~mA} \mathrm{~cm}$. The spectra show a decay of the Raman transitions of ethanol and the appearance of new bands. The significant bands of ethanol are summarized in Table I.

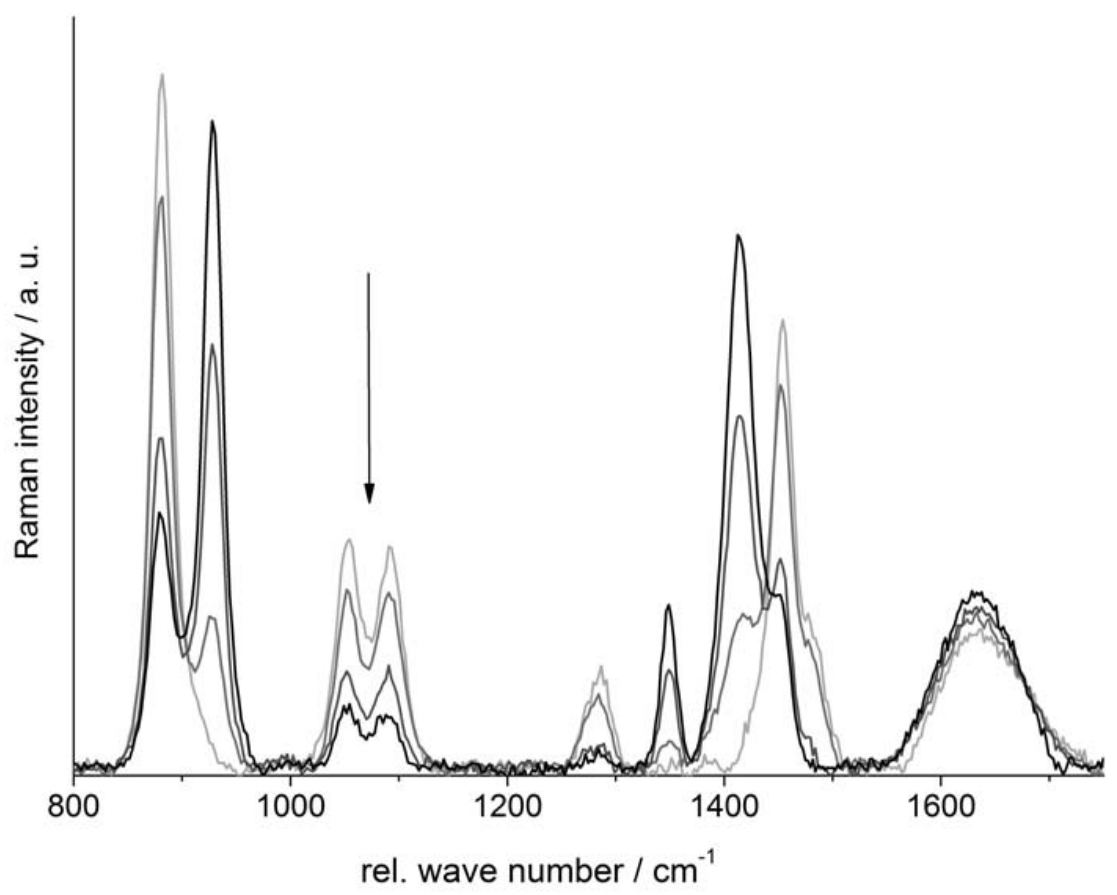

Figure 5. Raman reaction spectrum of the ethanol oxidation (light grey: start, grey: $8 \mathrm{~h}$, dark grey: $26 \mathrm{~h}$, black: $35 \mathrm{~h}$, increasing peaks: acetate). The arrow indicates the region in which a possible carbonate peak should appear.

TABLE I. Raman bands of ethanol (9), (10).

\begin{tabular}{ccc}
\hline wave number $/ \mathbf{~ c m}^{-1}$ & intensity & vibration \\
\hline 882 & $\mathrm{~s}$ & $\mathrm{v}_{\mathrm{s}}(\mathrm{CC})$ \\
1052 & $\mathrm{~m}$ & $\mathrm{v}_{\mathrm{s}}(\mathrm{CO})$ \\
1093 & $\mathrm{~m}$ & $\mathrm{v}_{\mathrm{s}}(\mathrm{CC})$ \\
1286 & $\mathrm{w}$ & $\gamma\left(\mathrm{CH}_{2}\right)$ \\
1454 & $\mathrm{~s}$ & $\delta\left(\mathrm{CH}_{3}\right)$ \\
\hline
\end{tabular}

$v_{\mathrm{s}}$ : stretch mode of the denoted bond; $\gamma, \delta$ : deformation modes

The new bands are unambiguously assigned to Raman transitions originated from acetate. The significant signals of acetate are summarized in Table II. A significant Raman band for the possible by-product acetaldehyde would appear at $1718 \mathrm{~cm}^{-1}$. Since this transition is missing, we conclude that acetaldehyde does not occur in detectable amounts during reaction. The intensive carbonate band within the chosen detection range 
would be expected at $1073 \mathrm{~cm}^{-1}$. The Raman transition of this possible by-product is located in between two adjacent ethanol transitions as indicated by an arrow in Fig. 5 .

TABLE II. Raman bands of acetate (11), (12).

\begin{tabular}{ccc}
\hline wavenumber $/ \mathbf{c m}^{-1}$ & intensity & vibration \\
\hline 929 & $\mathrm{~s}$ & $\mathrm{v}_{\mathrm{s}}(\mathrm{CC})$ \\
1350 & $\mathrm{w}$ & $\delta\left(\mathrm{CH}_{3}\right)$ \\
1415 & $\mathrm{~s}$ & $\mathrm{v}_{\mathrm{s}}(\mathrm{CO})$ \\
\hline
\end{tabular}

$v_{\mathrm{s}}$ : stretch mode of the denoted bond; $\delta$ : deformation modes

Fig. 6a presents the part of the Raman spectrum in which two adjacent ethanol bands are located. A band-shape analysis of this spectrum section proves the absence of a possible carbonate transition (Fig. 6b). Thus, a complete oxidation to carbonate as a possible reaction path can be distinctly excluded.

With respect to the absent carbon dioxide signal, the sensitivity of the Raman measurements was checked. For this, the $24 \mathrm{~h}$ measurement was repeated with compressed air while all other reaction parameters were maintained. The use of compressed air instead of $\mathrm{CO}_{2}$-free synthetic air let carbon dioxide dissolve in the alkaline membrane and carbonate diffuses into the electrolyte. Under these conditions small amounts of carbonate could be recorded as seen in Fig. 6c and Fig. 6d.

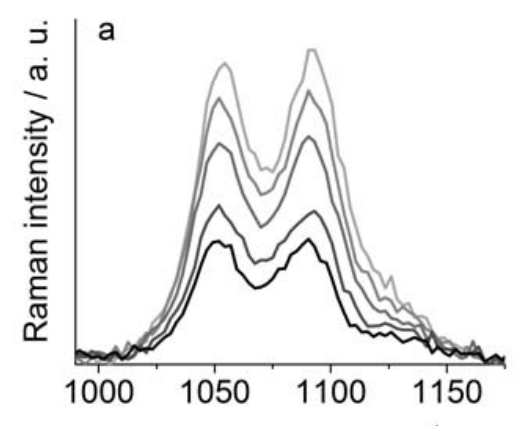

rel. wave number $/ \mathrm{cm}^{-1}$

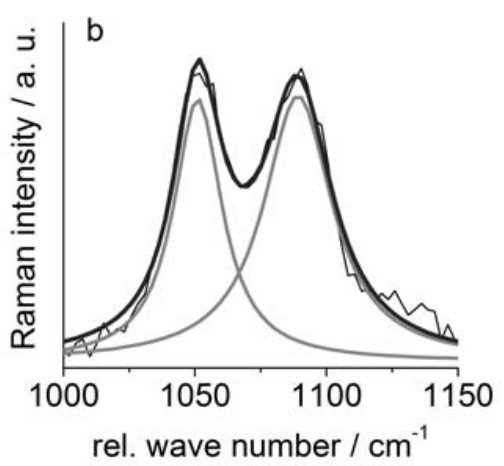

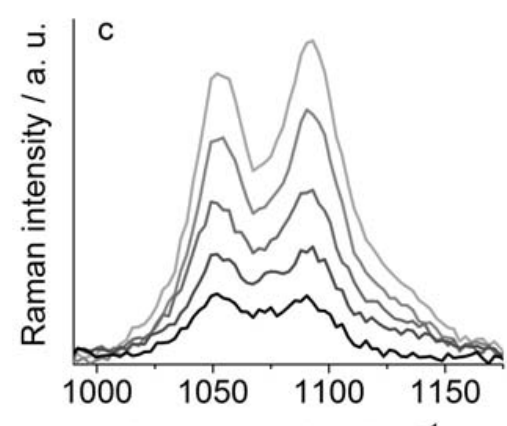

rel. wave number $/ \mathrm{cm}^{-1}$

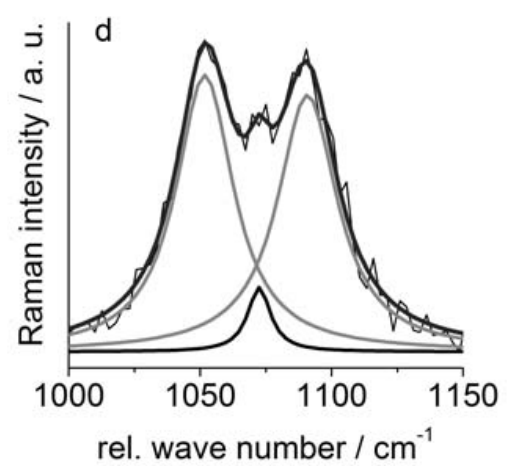

Figure 6. Time-sequence of Raman spectra and fitted spectra in the range of the carbonate peak; synthetic air (a, b) and compressed air (c, d). 
The sequence of reaction spectra exhibits both a linear decrease of the ethanol transitions and a linear increase of acetate signals during the complete time in which the reaction was pursued. This uniform reaction from ethanol to acetate indicates a direct chemical conversion without the inclusion of intermediates. After $24 \mathrm{~h}$ the loss of ethanol within the fuel amounted $396 \mathrm{mmol}$ while acetate was generated to $132 \mathrm{mmol}$. This implies that only one-third of the ethanol has been transformed into acetate. Since byproducts are not detected in the Raman spectra, the missing two-thirds of ethanol are attributed to diffusive losses through the membrane. A strong evidence for this assumption is the appearance of ethanol as the main part in the cathodic exhaust collected during the reaction under normal operating conditions. This was also proven by Raman spectroscopy.

If the cell is run under OCV conditions, traces of acetaldehyde and pre-stages of polymerization products as for instance crotonaldehyde were also found next to ethanol and water. These products were identified by UV-Vis absorption spectroscopy and mass spectroscopy. The occurrence of aldehydes on the cathode side seems to be a consequence of pure chemical oxidation in air since the absorption spectroscopy reveals no evidence for the presence of these aldehydes in the electrolyte.

Concluding, this contribution has shown that reactions within fuel cell can be well investigated by inserting a flow through cell into the anodic fuel cycle. Since low numbers of signals are generally characteristic for Raman spectra, compositions of mixtures can be easily analyzed by Raman spectroscopy. This property facilitates the pursue of chemical reactions. All in all, since this setup enables a quick change of MEA units and fuels, reactions of various fuels at different catalysts can be investigated by this approach.

\section{References}

1. C. Bianchini and P.K. Shen, Chemical Reviews, 109, 4183 (2009).

2. Z.X. Liang, T.S. Zhao, J.B. Xu and L.D. Zhu, Electrochimica Acta, 54, 2203 (2009).

3. C. Bianchini, V. Bambagioni, J. Filippi, A. Marchionni, F. Vizza, P. Bert and A. Tampucci, Electrochemistry Communications, 11, 1077 (2009).

4. X. Fang, L. Wang, P.K. Shen, G. Cui and C. Bianchini, Journal of Power Sources, 195, 1375 (2010).

5. J.S. Spendelow and A. Wieckowski, Physical Chemistry Chemical Physics, 9, 2654 (2007).

6. S.C.S. Lai and M.T.M. Koper, Physical Chemistry Chemical Physics, 11, 10446 (2009).

7. G. Cui, S. Song, P.K. Shen, A. Kowal and C. Bianchini, The Journal of Physical Chemistry, 113, 15639 (2009).

8. H.A. Rigby, C.J. Danby and C.N. Hinshelwood, Journal of the Chemical Society, 234 (1948).

9. J.R. Durig, W.E. Bucy, C.J. Wurrey and L.A. Carrelra, Journal of Raman Spectroscopy, 79, 988 (1975).

10. J.F. Mammone, S.K. Sharma and M. Nicol, The Journal of Physical Chemistry, 84, 3130 (1980). 
11. M. Johnson, Spectrochimica Acta Part A: Molecular Spectroscopy, 37, 899 (1981).

12. M. de Veij, P. Vandenabeele, T. De Beer,J. P. Remon, and L. Moens, Journal of Raman Spectroscopy, 40, 297 (2009). 